\title{
Long-Term Follow Up of the Erectile Function of Testicular Cancer Survivors
}

\begin{abstract}
Francesco Pallotti ${ }^{1}$, Alessandra Petrozzi ${ }^{1}$, Francesco Cargnelutti ${ }^{1}$, Antonio Francesco Radicioni ${ }^{2}$, Andrea Lenzi ${ }^{1}$, Donatella Paoli ${ }^{1 *}$ and Francesco Lombardo ${ }^{1}$

${ }^{1}$ Laboratory of Seminology-Sperm Bank Loredana Gandini, Department of Experimental Medicine, Sapienza University of Rome, Rome, Italy, ${ }^{2}$ Hormone Laboratory, Department of Experimental Medicine, Sapienza University of Rome, Rome, Italy
\end{abstract}

The diagnosis of testicular cancer (TC) can have a considerable and persistent impact on a patient's sexuality, especially given its location. The high prevalence of TC in young adults, and the good prognosis, explain the great interest in sexual dysfunction and its influence on post-treatment quality of life. The aim of this study was to evaluate the impact of the diagnosis and treatments (inguinal orchiectomy and chemotherapy) on sex life. For this purpose, we recruited $241 \mathrm{TC}$ patients attending the Laboratory of Seminology-Sperm Bank "Loredana Gandini" for sperm cryopreservation (mean age $31.3 \pm 6.9$ years) and 223 cancer-free healthy men who were undergoing andrological screening (mean age $32.0 \pm 7.7$ years). The IIEF-15 questionnaire was administered at the baseline (post-orchiectomy, pre-chemotherapy-T0) and at 6 (T1), 12 (T2), 18 (T3), 24 (T4), 48 months (T5) and > 5 years (T6, median 96 months) after chemotherapy to all patients, to evaluate the following domains: erectile function (EF), orgasmic function (OF), sexual desire (SD), intercourse satisfaction (IS) and overall satisfaction (OS). A subgroup of patients also underwent blood sex hormone analysis for further correlations with IIEF scores. At the baseline, 37.7\% of patients had erectile dysfunction (EF score <26) and all IIEF domains except OF showed significantly lower scores than in controls $(p<0.001)$. Long-term follow-up revealed persistently lower scores in TC survivors than in controls for EF, SD, IS, and OS. Furthermore, most IIEF domains did not improve significantly in TC patients during the duration of the follow-up, with the exception of EF, which showed a significant improvement from T2. Finally, no significant correlation was found between hormone levels (gonadotropin and testosterone) and IIEF-15 scores. In conclusion, TC and its treatment have a significant effect on sexuality. The absence of a clear correlation with biochemical hypogonadism suggests that this may to a large extent be due to the surgical procedure itself, or to the psychological impact of a cancer diagnosis.

Keywords: testicular cancer, cancer survivors, orchiectomy, sexual function, erectile dysfunction, IIEF

\section{INTRODUCTION} Lombardo F (2019) Long-Term Follow

Up of the Erectile Function of Testicular Cancer Survivors.

Front. Endocrinol. 10:196. doi: 10.3389/fendo.2019.00196
Alongside cardiovascular disease, cancer is currently the main cause of mortality worldwide. Italian cancer registers show that nearly $5 \%$ of the population has received a diagnosis of cancer (1). However, modern treatments mean that the life expectancy of about $60 \%$ of juvenile and young adult cancer survivors is comparable to that of the general population. 
Men in reproductive age are mainly affected by testicular cancer (TC) and lymphomas, but despite the high incidence, their 5-year survival rates are above $80-90 \%(2,3)$. These cancer survivors will therefore have to live with the long-term physical and psychological consequences of both their treatments (surgery, chemotherapy, radiotherapy) and the diagnosis itself (4, 5). This has important health, social and economic repercussions, as these long-term consequences affect men in their working and reproductive years, affecting their physical capabilities as well as their reproductive and sexual health. According to the $\mathrm{WHO}$, reproductive health is defined as a "state of complete physical, mental and social well-being and not merely the absence of disease or infirmity, in all matters relating to the reproductive system, and to its functions and processes" (6). Sexual health should in fact be considered as a complex interaction of multiple factors including social and cultural aspects, individual experiences, and self-image. Cancer and its treatments should certainly be considered as capable of disrupting sex life, but many patients find it difficult to discuss these problems and there is a lack of consensus on valid outcome measures for assessing sexual function in cancer patients on the basis of a broader definition of sexual health (7)-issues yet to be faced in common practice or research.

Most knowledge of male sexual dysfunction after cancer pertains to prostate cancer after invasive surgical procedures and hormonal treatments: however, this is not representative of other situations (8). The sexological features of testicular cancer have been investigated by several authors, revealing associations with perceived loss of masculinity and sexual function, which paves the way for psycho-organic sexual dysfunctions (4). Orchiectomy itself can alter the perception of body image, potentially manifesting as reduced libido and sexual gratification linked to the psychological stress of not "being normal" (9). The cancer diagnosis itself is a moment of intense psychological distress and, although literature reports vary widely, about one-third of patients with testicular cancer report erectile dysfunction and/or ejaculation disorders (10). Invasive and destructive surgery such as retroperitoneal lymph node dissection increases the frequency of such dysfunctions (10-12). However, most data focus on either the short- or the long-term consequences of therapy and reports of thorough longitudinal follow-up from diagnosis to long-term survivorship are rare. The aim of this study is to evaluate the effect of TC after orchiectomy and provide a complete follow-up in order to highlight possible short- and long-term sexological changes after treatment.

\section{MATERIALS AND METHODS}

\section{Patients}

The study was approved by our University Hospital's institutional review board (Ethical Committee Policlinico Umberto IUniversity of Rome "Sapienza") and all patients gave informed written consent. We recruited 241 sexually active consecutive patients (mean age $31.3 \pm 6.9$ years, range 18-52) with a recent diagnosis of testicular cancer who attended the Laboratory of Seminology-Sperm Bank "Loredana Gandini" between 2006 and 2018 for sperm cryopreservation before any cancer treatment. All patients had undergone orchiectomy within the previous 30 days.

As the control group, we recruited 223 healthy subjects (mean age $32.0 \pm 7.7$ years, range 18-55) who attended the Endocrinology and Andrology outpatient clinic of the Department of Experimental Medicine in the same period for idiopathic primary infertility. Subjects with hypogonadism and other endocrine disorders, diabetes, hypertension, cryptorchidism, history of cancer and/or previous chemo/radiotherapy, history of urogenital surgery, Klinefelter Syndrome and other chromosomal abnormalities or any genetic diseases were excluded. Both patients and controls underwent a thorough medical history and a general and andrological physical examination, and were administered the International Index of Erectile Function 15 questionnaire (IIEF-15) to evaluate sexual function. The IIEF-15 was administered to TC patients at the post-orchiectomy baseline before chemotherapy (T0) and at 6 (T1), 12 (T2), 18 (T3), 24 (T4), and 48 months (T5) after chemotherapy, with a final follow-up between 5 and 12 years post-chemotherapy (T6, median 96 months). Each patient underwent the baseline evaluation and at least one follow-up. A subgroup of TC patients also underwent blood hormone tests (FSH, LH, total Testosterone) for later comparison with healthy controls to investigate any correlations with IIEF scores. This subgroup patients underwent blood hormone analysis at T0, T1, and $\mathrm{T} 2$.

\section{Hormone Analysis}

Blood samples were collected at $8.00 \mathrm{a} . \mathrm{m}$. after at least $8 \mathrm{~h}$ of overnight fasting for measurement of $\mathrm{FSH}$, luteinizing hormone (LH) and total testosterone. Serum FSH, LH, and testosterone were measured by chemiluminescent microparticle immunoassay (CMIA, Architect System; Abbott Laboratories, Abbott Park, IL, USA), with detection limits of $0.05 \mathrm{mIU} / \mathrm{ml}$, $0.07 \mathrm{mIU} / \mathrm{ml}$, and $0.28 \mathrm{nmol} / \mathrm{l}$, respectively. Intra- and interassay coefficients of variation were 3.1 and $7.0 \%$ at $3.2 \mathrm{mIU} / \mathrm{ml}$ (FSH), 3.6 and $5.1 \%$ at $3.3 \mathrm{mIU} / \mathrm{ml}(\mathrm{LH})$, and 2.1 and $3.6 \%$ at $10.08 \mathrm{nmol}$ (total testosterone). Normal ranges for adults were $1.38-9.58 \mathrm{mIU} / \mathrm{ml}$ (FSH), $1.80-8.16 \mathrm{mIU} / \mathrm{ml}(\mathrm{LH})$, and 9.4-33.5 $\mathrm{nmol} / \mathrm{l}$ (total testosterone).

\section{IIEF-15}

Sexual function can be evaluated in a reassuring and comfortable setting with self-administered questionnaires. One of the most widely used in both clinical practice and research is IIEF15. This multidimensional tool enables the rapid, reliable and reproducible measurement of several domains of sexual function (13). It was developed to enable the evaluation of patients' sexuality in clinical trials for erectile dysfunction with high sensitivity and specificity. The advantage of self-administration is that it is perceived by patients as less invasive and burdensome than a direct interview. The classic form has 15 items grouped into five domains: erectile function (EF), questions $1-5$ and 15; orgasmic function (OF), questions 9-10; sexual desire (SD), questions 11-12; intercourse satisfaction (IS), questions 6-8; and general satisfaction (GS), questions 13-14. Generally, a 
score below 26 in the EF domain is considered diagnostic for erectile dysfunction.

\section{Statistical Analysis}

Continuous variables are presented as mean, median and standard deviation. Differences between groups were evaluated by ANOVA or Kruskal-Wallis test, based on data distribution as evaluated by Kolmogorov-Smirnov test. Post-hoc results were corrected using the Bonferroni method for multiple comparisons. Categorical variables are presented as counts and percentages and were compared by $\chi^{2}$ test. Statistically significant correlations among the variables examined were evaluated using Spearman's rank correlation test. The probability values are 2 -sided and a $p$-value $<0.05$ was considered statistically significant. All computations were carried out with Statistical Package for the Social Sciences (SPSS) 25.0 (SPSS Inc., Chicago, USA).

\section{RESULTS}

\section{Pre-therapy}

Table 1 describes the demographics of the recruited TC patients and control subjects. The TC and control groups were comparable in age, BMI and percentage of smokers. The baseline prevalence of erectile dysfunction as self-reported through the IIEF (EF domain score <26) was 37.8\% (91/241) in TC patients against $9.9 \%(22 / 223)$ in the control group $\left(\chi^{2} p<0.001\right)$. Erectile dysfunction was severe in $23.2 \%$ $(56 / 241)$, moderate in $4.1 \%(10 / 241)$ and mild in $10.4 \%(25 / 241)$ of TC patients, while all cases in the control group were mild. The baseline comparison of TC and CTR groups is presented in Table 2: all IIEF-15 domain scores were significantly worse in patients than in controls (all $p<0.001$ ), with the exception of orgasmic function $(p=0.334)$. No significant correlations were found between IIEF scores and age, BMI, smoking status, cigarettes smoked/day and years of smoking in either group.

\section{Post-therapy}

All patients underwent a chemotherapy regimen only, as indicated in Table 1. IIEF scores from longitudinal follow up are compared against healthy controls are shown in Table 3. Kruskal Wallis test with post-hoc corrections for multiple comparisons (Bonferroni) revealed that:

- ED domain scores had improved significantly 1 year post-chemotherapy (T0 vs. T2: $p=0.001$ ), with further improvements at T3 and T4 (T0 vs. T3: $p=0.014$; T0 vs. T4: $p$ $=0.002$ ) (Figure 1, Table 3). However, there was an increase in the prevalence of erectile dysfunction at T5, with a significant reduction in ED domain scores; this seemed to persist at T6. Compared to controls, ED scores remained significantly worse at $\mathrm{T} 1$ then returned to a level comparable with healthy controls (Table 3).

- OF domain scores showed a trend of improvement from the baseline $(p=0.070)$, but pairwise comparisons against both baseline and controls did not reach statistical significance (Table 3 ).
TABLE 1 | Testicular cancer and Control group demographics: continuous data are presented as mean \pm SD, median (in brackets) and 25-75th percentile of data distribution; categorical data as percentage and count.

\begin{tabular}{|c|c|c|}
\hline & $\begin{array}{l}\text { Testicular cancer } \\
\text { (241 pts) }\end{array}$ & $\begin{array}{l}\text { Controls } \\
\text { (223 pts) }\end{array}$ \\
\hline \multirow{2}{*}{$\begin{array}{l}\text { Age at } \\
\text { diagnosis } \\
\text { (years) }\end{array}$} & $\begin{array}{l}31.3 \pm 6.9 \\
(31.0)\end{array}$ & $\begin{array}{l}32.0 \pm 7.7 \\
(32.0)\end{array}$ \\
\hline & $26.0-36.0$ & $26.0-37.0$ \\
\hline \multirow[t]{2}{*}{ BMI $\left(k g / m^{2}\right)$} & $\begin{array}{l}24.9 \pm 3.0 \\
(24.5)\end{array}$ & $\begin{array}{l}24.6 \pm 2.7 \\
(24.1)\end{array}$ \\
\hline & 23.0-26.7 & $22.7-25.9$ \\
\hline \multirow[t]{2}{*}{ Smokers } & $19.5 \%$ & $23.3 \%$ \\
\hline & 47 pts & 52 pts \\
\hline \multirow[t]{2}{*}{ Cigarettes/day ${ }^{a}$} & $\begin{array}{l}11.4 \pm 8.5 \\
(10.0)\end{array}$ & $\begin{array}{l}11.3 \pm 8.5 \\
(10.0)\end{array}$ \\
\hline & $5.0-15.0$ & $5.0-15.0$ \\
\hline \multirow[t]{2}{*}{$\begin{array}{l}\text { Years of } \\
\text { smoking }^{a}\end{array}$} & $\begin{array}{l}12.3 \pm 6.6 \\
(10.0)\end{array}$ & $\begin{array}{l}10.6 \pm 6.2 \\
(10.0)\end{array}$ \\
\hline & 7.0-16.0 & $6.0-15.0$ \\
\hline Occupation & $\begin{array}{l}\text { Office worker (23.6\%) } \\
\text { Factory/heavy worker (15.3\%) } \\
\text { Freelance professional (13.9\%) } \\
\text { Student/university (9.7\%) } \\
\text { Police/military (2.8\%) } \\
\text { Driver (5.6\%) } \\
\text { Healthcare professional (4.2\%) } \\
\text { Unemployed (5.6\%) } \\
\text { Other (19.3\%) }\end{array}$ & $\begin{array}{l}\text { Office worker (18.1\%) } \\
\text { Factory/heavy worker (16.9\%) } \\
\text { Freelance professional (20.5\%) } \\
\text { Students/university (14.5\%) } \\
\text { Police/military (3.6\%) } \\
\text { Driver (3.6\%) } \\
\text { Healthcare professional (9.6\%) } \\
\text { Unemployed (2.4\%) } \\
\text { Other (10.8\%) }\end{array}$ \\
\hline $\begin{array}{l}\text { Histological } \\
\text { diagnosis }\end{array}$ & $\begin{array}{l}\text { 58.5\% Seminoma pT1-pT2 } \\
\text { 30.7\% Mixed germ cell tumor } \\
\text { pT1-pT2 } \\
\text { 8.0\% Embryonal carcinoma } \\
\text { pT1-pT2 } \\
2.8 \% \text { Yolk sac tumor }\end{array}$ & / \\
\hline $\begin{array}{l}\text { Chemotherapy } \\
\text { regimen }\end{array}$ & $\begin{array}{l}\text { BEP } 1-3 \text { cycles } \\
\text { cysplatin } 1 \text { cycle }\end{array}$ & / \\
\hline
\end{tabular}

${ }^{a}$ smokers only.

- SD, IS, and GS domain scores, although showing a trend of improvement, did not differ significantly from the baseline at any time points; however TC patients scored significantly worse than the controls for the entire duration of the study (Table 3 ).

\section{Sex Hormone Analysis}

The prevalence of biochemical hypogonadism (total testosterone $<8.0 \mathrm{nmol} / \mathrm{l}$ ) was $4.1 \%$ in the TC group; there were no hypogonadal patients in the control group. The Kruskal Wallis test with post-hoc corrections for multiple comparisons (Bonferroni) revealed that gonadotropin (both $\mathrm{FSH}$ and $\mathrm{LH}$ ) levels in the TC patients were higher both pre-chemotherapy and at T1 and T2 than in the controls (all $p<0.001$ ). Total testosterone at T0 was significantly lower than in the controls $(p$ $<0.001$ ), but there was no difference from the control groups at T1 or T2 (Table 4). Finally, no significant correlation was found between total testosterone levels and the score of any IIEF-15 domain. 


\section{DISCUSSION}

The trend of reduced mortality for various cancers, including testicular cancer, has increased clinicians' awareness of the importance of long-term quality of life after surgery and chemo-

TABLE 2 | Baseline testicular cancer IIEF scores vs. control group: continuous data are presented as mean $\pm \mathrm{SD}$, median (in brackets) and 25-75th percentile of data distribution.

\begin{tabular}{lccccc}
\hline & ED domain & OF domain & SD domain & IS domain & GS domain \\
\hline TC & $22.7 \pm 9.1$ & $8.2 \pm 1.9$ & $7.5 \pm 1.9$ & $8.3 \pm 4.7$ & $7.4 \pm 2.6$ \\
241 pts & $(27.0)$ & $(10.0)$ & $(8.0)$ & $(10.0)$ & $(8.0)$ \\
& $20.0-29.0$ & $8.0-10.0$ & $6.0-9.0$ & $7.0-12.0$ & $6.0-10.0$ \\
CTR & $27.9 \pm 2.6$ & $8.9 \pm 1.2$ & $8.9 \pm 1.2$ & $12.6 \pm 1.9$ & $9.0 \pm 1.3$ \\
223 pts & $(28.5)$ & $(10.0)$ & $(9.0)$ & $(13.0)$ & $(9.0)$ \\
& $27.0-30.0$ & $8.0-10.0$ & $8.0-10.0$ & $11.5-14.0$ & $8.0-10.0$ \\
$P$-value & $<0.001$ & 0.334 & $<0.001$ & $<0.001$ & $<0.001$
\end{tabular}

(Mann Whitney $U$ test). EF, erectile function; OF, orgasmic function; $S D$, sexual desire; IS, intercourse satisfaction; GS, general satisfaction. and radiotherapy. Recent literature has focused on cancers involving the testes and genitalia $(8,12,14,15)$, but sexual function in male survivors of other frequent cancers has also been investigated $(16,17)$. In general, while TC survivors maintain or recover a good quality of life, investigation of their sex life reveals marked changes (18-20). Carpentier et al. highlighted that the diagnosis and therapy stages are associated with peak levels of anxiety and concern, which then drop in the post-treatment period. Similarly, stress-related central inhibition of sexual function results in a rise in libido, erection, and ejaculation disorders during cancer treatments (4). In fact, sexual dysfunctions in TC patients may arise from a combination of treatment-related physical side effects (genital mutilation, reduced testosterone levels, chronic pain, and other residual side effects) and psychological vulnerability (anxiety, fear, mood disorders, etc.) (Figure 2) (21). A possible underlying cause may be the induction of iatrogenic hypogonadism: in fact, orchiectomy, chemotherapy, and radiotherapy may all induce gonadal dysfunction. Our group recently found that a cohort of orchiectomized TC patients prior to cancer treatment had increased levels of gonadotropins and reduced

TABLE 3 | IIEF scores of testicular cancer and control group: continuous data are presented as mean \pm SD, median (in brackets) and 25-75th percentile of data distribution, while categorical data as percentage and counts.

\begin{tabular}{|c|c|c|c|c|c|c|}
\hline & $\begin{array}{c}\text { ED } \\
\text { domain }\end{array}$ & $\begin{array}{c}\text { OF } \\
\text { domain }\end{array}$ & $\begin{array}{c}\text { SD } \\
\text { domain }\end{array}$ & $\begin{array}{c}\text { IS } \\
\text { domain }\end{array}$ & $\begin{array}{c}\text { GS } \\
\text { domain }\end{array}$ & $\begin{array}{c}\text { Erectile } \\
\text { dysfunction } \\
(\%)\end{array}$ \\
\hline \multirow[t]{2}{*}{$\begin{array}{l}\text { T0 } \\
241 \text { pts }\end{array}$} & $\begin{array}{c}22.7 \pm 9.1^{a} \\
(27.0)\end{array}$ & $\begin{array}{l}8.2 \pm 1.9 \\
(10.0)\end{array}$ & $\begin{array}{c}7.5 \pm 1.9^{a} \\
(8.0)\end{array}$ & $\begin{array}{c}8.3 \pm 4.7^{a} \\
(10.0)\end{array}$ & $\begin{array}{c}7.4 \pm 2.6^{a} \\
(8.0)\end{array}$ & $\begin{array}{l}37.8 \%{ }^{d} \\
(91 / 241)\end{array}$ \\
\hline & 20.0-29.0 & $8.0-10.0$ & $6.0-9.0$ & $7.0-12.0$ & $6.0-10.0$ & \\
\hline \multirow[t]{2}{*}{$\begin{array}{l}\text { T1 } \\
74 \text { pts }\end{array}$} & $\begin{array}{c}24.1 \pm 8.6^{C} \\
(28.0)\end{array}$ & $\begin{array}{c}8.8 \pm 2.4 \\
\quad(10.0)\end{array}$ & $\begin{array}{c}8.0 \pm 1.7^{b} \\
(8.0)\end{array}$ & $\begin{array}{c}8.7 \pm 4.2^{b} \\
(10.0)\end{array}$ & $\begin{array}{c}7.9 \pm 2.3^{a} \\
(8.0)\end{array}$ & $\begin{array}{l}28.4 \% d \\
(21 / 74)\end{array}$ \\
\hline & $24.0-30.0$ & $9.0-10.0$ & $7.0-9.0$ & $8.0-11.0$ & $8.0-10.0$ & \\
\hline \multirow[t]{2}{*}{$\begin{array}{l}\text { T2 } \\
110 \text { pts }\end{array}$} & $\begin{array}{c}25.8 \pm 7.1 \\
(29.0)\end{array}$ & $\begin{array}{c}8.8 \pm 2.3 \\
(10.0)\end{array}$ & $\begin{array}{c}7.6 \pm 1.7^{b} \\
(8.0)\end{array}$ & $\begin{array}{c}9.4 \pm 3.6^{b} \\
(10.0)\end{array}$ & $\begin{array}{c}7.9 \pm 2.2^{\mathrm{a}} \\
(8.0)\end{array}$ & $\begin{array}{l}23.6 \% d \\
(26 / 110)\end{array}$ \\
\hline & 26.0-30.0 & $9.0-10.0$ & $7.0-9.0$ & $8.0-12.0$ & $7.0-10.0$ & \\
\hline \multirow[t]{2}{*}{$\begin{array}{l}\text { T3 } \\
60 \text { pts }\end{array}$} & $\begin{array}{c}26.5 \pm 6.3 \\
(29.0)\end{array}$ & $\begin{array}{c}8.7 \pm 2.3 \\
(10.0)\end{array}$ & $\begin{array}{c}7.6 \pm 1.6^{b} \\
(8.0)\end{array}$ & $\begin{array}{c}9.7 \pm 3.7^{b} \\
(10.0)\end{array}$ & $\begin{array}{c}8.0 \pm 2.2^{b} \\
(8.0)\end{array}$ & $\begin{array}{l}18.3 \% d \\
(11 / 60)\end{array}$ \\
\hline & 27.0-30.0 & $8.0-10.0$ & 7.0-9.0 & $9.0-12.0$ & $7.0-10.0$ & \\
\hline \multirow[t]{2}{*}{$\begin{array}{l}\text { T4 } \\
75 \text { pts }\end{array}$} & $\begin{array}{c}26.9 \pm 5.7 \\
(29.0)\end{array}$ & $\begin{array}{c}9.2 \pm 1.7 \\
(10.0)\end{array}$ & $\begin{array}{c}8.0 \pm 1.5^{b} \\
(8.0)\end{array}$ & $\begin{array}{c}10.0 \pm 3.3^{b} \\
(11.0)\end{array}$ & $\begin{array}{c}8.5 \pm 1.7^{b} \\
(9.0)\end{array}$ & $\begin{array}{l}16.0 \% \mathrm{~d} \\
(12 / 75)\end{array}$ \\
\hline & 27.0-30.0 & $9.0-10.0$ & 7.0-9.0 & $9.0-12.0$ & $8.0-10.0$ & \\
\hline \multirow[t]{2}{*}{$\begin{array}{l}\text { T5 } \\
67 \text { pts }\end{array}$} & $\begin{array}{c}24.9 \pm 8.0 \\
(28.0)\end{array}$ & $\begin{array}{c}8.0 \pm 2.9 \\
(10.0)\end{array}$ & $\begin{array}{c}7.5 \pm 1.8^{b} \\
(8.0)\end{array}$ & $\begin{array}{c}8.9 \pm 4.0^{b} \\
(9.0)\end{array}$ & $\begin{array}{c}7.8 \pm 2.3^{a} \\
(8.0)\end{array}$ & $\begin{array}{c}25.4 \% d \\
(17 / 67)\end{array}$ \\
\hline & 25.0-30.0 & $6.0-10.0$ & $6.0-9.0$ & $8.0-12.0$ & $7.0-10.0$ & \\
\hline \multirow[t]{2}{*}{$\begin{array}{l}\text { T6 } \\
36 \text { pts }\end{array}$} & $\begin{array}{c}25.2 \pm 7.3 \\
(28.0)\end{array}$ & $\begin{array}{c}9.0 \pm 2.0 \\
\quad(10.0)\end{array}$ & $\begin{array}{c}7.7 \pm 1.6^{b} \\
(8.0)\end{array}$ & $\begin{array}{c}9.8 \pm 3.6^{b} \\
(10.0)\end{array}$ & $\begin{array}{c}8.2 \pm 2.0^{C} \\
(8.0)\end{array}$ & $\begin{array}{l}30.5 \% d \\
(11 / 36)\end{array}$ \\
\hline & $24.0-30.0$ & $8.0-10.0$ & $7.0-9.0$ & $9.0-12.0$ & $8.0-10.0$ & \\
\hline \multirow[t]{2}{*}{$\begin{array}{l}\text { CTR } \\
223 \text { pts }\end{array}$} & $\begin{array}{c}27.9 \pm 2.6 \\
(28.5)\end{array}$ & $\begin{array}{c}8.9 \pm 1.2 \\
(10.0)\end{array}$ & $\begin{array}{c}8.9 \pm 1.2 \\
(9.0)\end{array}$ & $\begin{array}{c}12.6 \pm 1.9 \\
(13.0)\end{array}$ & $\begin{array}{c}9.0 \pm 1.3 \\
(9.0)\end{array}$ & $\begin{array}{c}9.9 \% \\
(22 / 223)\end{array}$ \\
\hline & 27.0-30.0 & $8.0-10.0$ & 8.0-10.0 & $11.5-14.0$ & 8.0-10.0 & \\
\hline$P$-value & $<0.001$ & 0.068 & $<0.001$ & $<0.001$ & $<0.001$ & // \\
\hline
\end{tabular}

(Kruskal Wallis test with Bonferroni correction for multiple comparisons). EF, erectile function; OF, orgasmic function; SD, sexual desire; IS, intercourse satisfaction; GS, general satisfaction. ${ }^{a} p<0.001$ vs. Controls

${ }^{b} p<0.01$ vs. Controls

${ }^{c} p<0.05$ vs. Controls

${ }^{d} \chi^{2} p<0.001$ vs. Controls. 


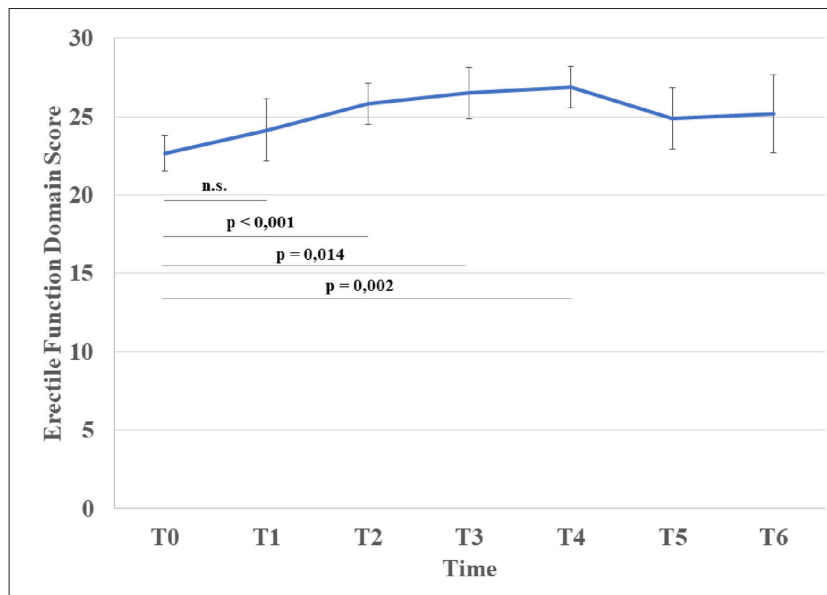

FIGURE 1 | Variation in mean erectile function domain score and statistical significance from TO (Bonferroni correction for multiple comparisons).

TABLE 4 | FSH, LH and total testosterone of testicular cancer and Control group: continuous data are presented as mean $\pm \mathrm{SD}$, median (in brackets) and 25-75th percentile of data distribution, while categorical data as percentage and counts.

\begin{tabular}{lcccc}
\hline & $\begin{array}{c}\text { FSH } \\
\text { (mUl/ml) }\end{array}$ & $\begin{array}{c}\text { LH } \\
\text { (mUl/ml) }\end{array}$ & $\begin{array}{c}\text { Total } \\
\text { testosterone } \\
\text { (nmol/l) }\end{array}$ & $\begin{array}{c}\text { Biochemical } \\
\text { hypogonadism } \\
\text { (\%) }\end{array}$ \\
\hline T0 & $7.6 \pm 6.3^{\mathrm{a}}$ & $4.6 \pm 4.1^{\mathrm{a}}$ & $17.9 \pm 6.1^{\mathrm{a}}$ & $4.1 \%$ \\
194 pts & $(6.1)$ & $(4.0)$ & $(17.0)$ & $(8 / 194)$ \\
T1 & $4.0-9.8$ & $2.7-5.6$ & $13.3-20.9$ & \\
68 pts & $14.3 \pm 8.9^{\mathrm{a}}$ & $6.6 \pm 3.5^{\mathrm{a}}$ & $19.2 \pm 6.7$ & $4.4 \%$ \\
& $(12.3)$ & $(5.6)$ & $(19.0)$ & $(3 / 68)$ \\
T2 & $7.3-19.7$ & $3.7-8.2$ & $15.0-21.6$ & \\
71 pts & $13.0 \pm 8.5^{\mathrm{a}}$ & $6.8 \pm 6.1^{\mathrm{a}}$ & $17.9 \pm 5.7$ & $2.8 \%$ \\
& $(10.0)$ & $(5.3)$ & $(17.9)$ & $(2 / 71)$ \\
CTR & $7.1-18.5$ & $3.8-7.4$ & $13.5-20.5$ & \\
223 pts & $4.7 \pm 4.5$ & $3.7 \pm 1.8$ & $20.2 \pm 7.1$ & $0.0 \%$ \\
& $(3.5)$ & $(3.3)$ & $(19.4)$ & $(0 / 223)$ \\
P-value & $2.3-5.4$ & $2.4-4.6$ & $15.1-24.4$ & \\
\hline
\end{tabular}

(Kruskal Wallis test with Bonferroni correction for multiple comparisons).

${ }^{a} p<0.001$ vs. CTR.

testosterone in comparison with healthy controls, albeit still within the normal range (22). Some authors have shown that gonadotropin alterations persist after chemotherapy, while about $10 \%$ of patients may suffer from low total testosterone levels after treatment or have a higher risk of late onset hypogonadism $(20,23-26)$. However, other authors found that chemotherapy had only mild effects on hormone levels $(27,28)$. In contrast, radiotherapy may affect testosterone levels for up to 5 years in TC patients who received testicular irradiation for contralateral carcinoma in situ (29), but direct testicular irradiation is not a standard treatment for TC patients and current radiotherapy protocols probably have only a minor effect on testicular function (20). In any case, whether or not altered gonadotropin and testosterone levels are the only determinant of sexual dysfunctions in TC patients is still under debate. The

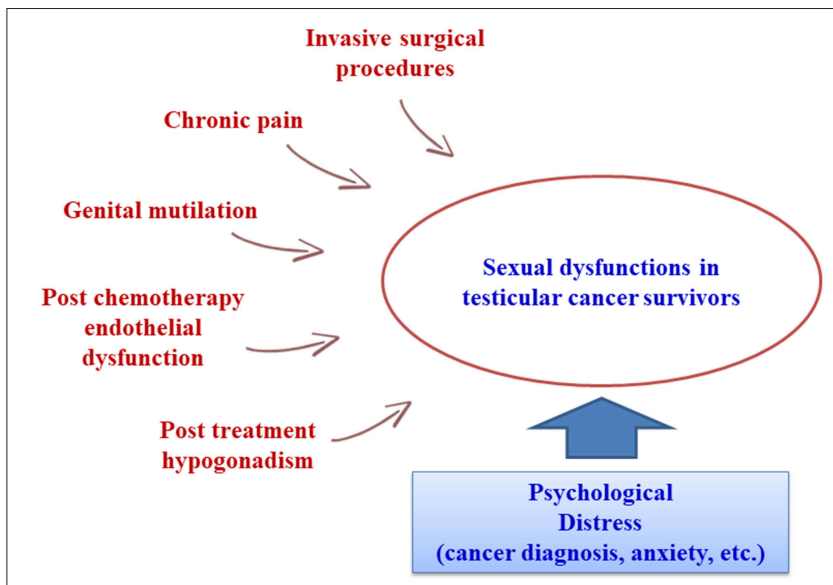

FIGURE 2 | Determinants of sexual dysfunction in testicular cancer survivors.

already cited study by Huddart et al. found that about $10 \%$ of post-therapy TC patients had biochemical hypogonadism, with worse sexual function than observed in non-hypogonadal TC survivors (20). However, a later study by Lackner et al. (30) found a higher percentage of post-treatment hypogonadism (26\%). These authors could not identify an unambiguous threshold level for testosterone associated with the onset of sexological symptoms, and hypothesized that each patient might have an individual threshold (30). In 2009, Eberard et al. published a caseload of 129 TC survivors 3-5 years post-therapy compared to an age-matched group of men without cancer, observing that TC survivors had a higher likelihood of low sexual desire (OR 6.7) and erectile dysfunction (OR 3.8) compared to controls, but that these conditions could not be predicted from the presence of hypogonadism (31). However, these results are limited by the lack of the pre-treatment status of the TC patients. Subsequent studies also failed to find a clear association between sexual dysfunctions and biochemical hypogonadism (28, 32-34). In conclusion, most of the literature evidence suggests that the high prevalence of sexual dysfunctions cannot be justified by the relatively low prevalence of biochemically detected hypogonadism. Another hypothesis could link sexual dysfunctions to specific treatment modalities. The side effects of several chemotherapy drugs include endothelial damage, angiopathy, and peripheral neuropathy, which may be linked to erectile and ejaculatory disorders $(35,36)$. Radiotherapy can cause sexual dysfunctions by inducing damage to the cavernous nerve and/or progressive fibrosis of the cavernous tissue and endothelial damage, which can become clinically evident through the onset of erectile dysfunction even several years posttreatment (37). However, the literature data are inconsistent, as several studies report no significant associations between sexual dysfunctions and specific treatment modalities (31), while others report the significant influence of either chemo- or radiotherapy $(14,15,32,38)$. The reason for this variability could be the use of different combinations of these therapies with different surgical procedures (tailored to the patient in relation to various clinical parameters such as stage, etc.), while individual variability might also induce different outcomes. Kim et al. reported 
that surgery combined with chemotherapy produced a higher incidence of reduced libido and ejaculatory disorders, while surgery combined with radiotherapy was followed by a greater incidence of erectile dysfunction (32). More recently, Bandak et al. observed that each treatment modality carried an increased risk of erectile and orgasmic dysfunctions, with multimodal treatment associated with the highest risk (15). Invasive surgical procedures such as retroperitoneal lymph node dissection are known to have a strong impact on sexual function (especially ejaculatory and orgasm disorders and impaired satisfaction) (12). Several studies have confirmed a worse sexological outcome after retroperitoneal surgery (lymph node dissection and/or resurgery for relapse after chemotherapy) as a consequence of ejaculatory nerve damage during the procedure $(10,12,21,39$, 40). Another issue is the trend of sexual dysfunction over time in TC survivors, as most literature studies are cross-sectional and only a few longitudinal studies are available. We currently expect a higher incidence of SD soon after the orchiectomy and the end of cancer treatment. Tuinman et al. found low IIEF scores post-orchiectomy and 3 months post-treatment, with significant improvements after 1 year of follow-up (41). These results were comparable to those of other studies focusing on SD within the first year after treatment $(5,42,43)$. Long-term pre- and post-therapy comparisons are rare. Aass et al. found that sexual problems persisted in about $30 \%$ of TC survivors 36 months posttreatment (39), while Böhlen et al. reported no significant prevs. post-therapy differences in sexual function after at least 32 months of follow-up (44). Despite the general agreement on the presence of sexual dysfunctions in TC survivors, the absence of longitudinal long-term follow-up and the lack of standardization in the measurement of sexual function limit the assessment of their true patient burden. Data comparison and generalization are difficult, as different papers use a variety of tools and methods to evaluate sexual function. Moreover, in common with most sexological questionnaires, IIEF is poor at discriminating to what extent sexual dysfunctions are secondary to the organic sequalae of cancer treatments (45). In accordance with most of the available literature data, our results clearly show that TC patients undergoing orchiectomy and chemotherapy suffered from a higher degree of sexual dysfunctions than a control population of cancer-free subjects. These mainly presented as erectile dysfunctions, but also as impaired sexual desire and satisfaction. The incidence of orgasmic dysfunction did not differ significantly from controls. It is worth noting that the presence of these sexual dysfunctions at the baseline suggests that they might be induced by orchiectomy. However, it is difficult to find a biological relationship. We found a lower incidence (about 4\%) of biochemical hypogonadism at the baseline (total testosterone $<8.0 \mathrm{nmol} / \mathrm{l}$ ) than in other reports, but like them, we found no significant correlation with sexual function domains $(20,30,31)$. This suggests that sexual dysfunctions are not explained by abnormal hormone levels consequent to orchiectomy and might instead be more closely associated with a psychological burden in these patients, which might coexist and be synergistic with treatment-induced hypogonadism. As the testicles are associated with masculinity, orchiectomy might well induce changes in body perception. In a caseload of $407 \mathrm{TC}$ patients, Rossen et al. observed that about $17 \%$ had a reduced perception of masculinity induced by orchiectomy. This was associated with a 9-fold increased risk of erectile dysfunction and a 15-fold increased risk of sexual discomfort (10). Wortel et al. reported that after orchiectomy, up to $50 \%$ of patients might complain of a distorted perception of body image (42). All of our patients underwent the insertion of a testicular prosthesis. This may have positively influenced their body perception, as suggested in a study by Catanzariti et al. (43), but whether and to what extent this might have contributed to the improved IIEF-15 scores in our study is unknown, and should be investigated in further studies. We also detected a significant improvement in erectile function post-therapy. Although some degree of erectile dysfunction persisted at all time points, the incidence constantly dropped in the first 2 years after treatment (up to T4) and the IIEF-15 erectile dysfunction scores improved and were comparable to the controls 1 year after treatment (T2). There was also a trend of improvement in sexual desire and in both intercourse and general satisfaction, but followup showed that they remained significantly worse than in the controls. To our knowledge, the present study is the longest monocentric follow-up currently available for the sexological evaluation of TC patients. Unfortunately, the generalizability of data comparisons against healthy controls might be reduced for long term follow-up, as the increased percentage of patients with erectile dysfunction at T5 and T6 may simply be due to their increased age and the consequent possible onset of other factors (hypertension and other cardiovascular diseases, use of medications, etc.) increasing the incidence of sexual dysfunctions, independently of TC and its treatments.

In conclusion, our data, from a large caseload compared to a control group of similar age and strengthened by the use of a validated psychometric tool, indicate that TC patients need adequate sexological counseling following diagnosis/orchiectomy and prior to chemotherapy. Discussing these aspects with patients could help them to cope with the disease and to understand that their erectile function should improve within a year after the end of treatment. Future studies should identify subjects who are more likely to suffer from SDs, thus permitting the better follow-up of these patients and enabling them to be offered all the support they need to maintain a satisfactory sex life and, consequently, a good general quality of life.

\section{DATA AVAILABILITY}

The datasets for this manuscript are not publicly available. If required, the data are available in our database upon request. Requests to access the datasets should be directed to donatella.paoli@uniroma1.it.

\section{AUTHOR CONTRIBUTIONS}

FL, FP and DP conceived the study; FP and FL wrote the article; FP, AP and FC acquired and analyzed the data; FL, 
FP and DP contributed to data interpretation; $A R$ and $A L$ manuscript revision.

\section{FUNDING}

This work was supported by a grant from the Italian Ministry of Education and Research (MIUR-PRIN 2015-

\section{REFERENCES}

1. AIRTUM working group. Italian cancer figures, report 2014: prevalence and cure of cancer in Italy. Epidemiol Prev. (2014) 38(6 Suppl. 1):1-122.

2. Dal Maso L, Guzzinati S, Buzzoni C, Capocaccia R, Serraino D, Caldarella A, et al. Long-term survival, prevalence, and cure of cancer: a populationbased estimation for 818902 Italian patients and 26 cancer types. Ann Oncol Off J Eur Soc Med Oncol. (2014) 25:2251-60. doi: 10.1093/annonc/ mdu383

3. Capocaccia R, Gatta G, Dal Maso L. Life expectancy of colon, breast and testicular cancer patients. An analysis of US-SEER population-based data. Ann Oncol. (2015) 26:1263-8. doi: 10.1093/annonc/mdv131

4. Carpentier MY, Fortenberry JD. Romantic and sexual relationships, body image, and fertility in adolescent and young adult testicular cancer survivors: a review of the literature. J Adolesc Health. (2010) 47:115-25. doi: 10.1016/j.jadohealth.2010.04.005

5. Brand S, Williams H, Braybrooke J. How has early testicular cancer affected your life? A study of sexual function in men attending active surveillance for stage one testicular cancer. Eur J Oncol Nurs. (2015) 19:278-81. doi: 10.1016/j.ejon.2014.11.001

6. WHO regional office for Europe. Fact sheet on SDGs - Sexual and Reproductive Health (SDG targets 3.7 and 5.6). (2017). Available online at: http://www.euro.who.int/_data/assets/pdf_file/0005/348008/Fact-sheetSDG-SRH-FINAL-04-09-2017.pdf?ua=1 (Accessed January 20, 2019).

7. Nagele E, Den Oudsten B, Greimel E, EORTC Quality of Life Group. How to evaluate sexual health in cancer patients: development of the EORTC sexual health questionnaire for cancer patients. Transl Androl Urol. (2015) 4:95-102. doi: $10.3978 /$ j.issn.2223-4683.2014.11.08

8. Katz A, Dizon DS. Sexuality after cancer: a model for male survivors. J Sex Med. (2016) 13:70-8. doi: 10.1016/j.jsxm.2015.11.006

9. Gilbert E, Ussher JM, Perz J, Wong WKT, Hobbs K, Mason C. Men's experiences of sexuality after cancer: a material discursive intra- psychic approach. Cult Health Sex. (2013) 158:881-95. doi: 10.1080/13691058.2013.789129

10. Rossen P, Pedersen AF, Zachariae R, Von Der Maase H. Sexuality and body image in long-term survivors of testicular cancer. Eur J Cancer. (2012) 48:571-8. doi: 10.1016/j.ejca.2011.11.029

11. Pühse G, Wachsmuth JU, Kemper S, Husstedt IW, Evers S, Kliesch S. Chronic pain has a negative impact on sexuality in testis cancer survivors. J Androl. (2012) 33:886-93. doi: 10.2164/jandrol.110.012500

12. Dimitropoulos K, Karatzas A, Papandreou C, Daliani D, Zachos I, Pisters LL, et al. Sexual dysfunction in testicular cancer patients subjected to post-chemotherapy retroperitoneal lymph node dissection: a focus beyond ejaculation disorders. Andrologia. (2016) 48:425-30. doi: 10.1111/and. 12462

13. Rosen RC, Riley A, Wagner G, Osterloh IH, Kirkpatrick J, Mishra A. The international index of erectile function (IIEF): a multidimensional scale for assessment of erectile dysfunction. Urology. (1997) 49:822-30. doi: 10.1016/S0090-4295(97)00238-0

14. Capogrosso P, Boeri L, Ferrari M, Ventimiglia E, La Croce G, Capitanio $\mathrm{U}$, et al. Long-term recovery of normal sexual function in testicular cancer survivors. Asian J Androl. (2016) 18:85-9. doi: 10.4103/1008-682X.149180

15. Bandak M, Lauritsen J, Johansen C, Kreiberg M, Skøtt JW, Agerbaek M, et al. Sexual function and quality of life in a national cohort of survivors of bilateral testicular cancer. Eur Urol Focus. (2018). doi: 10.1016/j.euf.2018.11.007 [Epub ahead of print].
2015XCR88M-006) and the University of Rome Sapienza Faculty of Medicine.

\section{ACKNOWLEDGMENTS}

The authors wish to thank Marie-Hélène Hayles for the English revision.

16. Arden-Close E, Eiser C, Pacey A. Sexual functioning in male survivors of lymphoma: a systematic review (CME). J Sex Med. (2011) 8:1833-41. doi: 10.1111/j.1743-6109.2011.02209.x

17. Haavisto A, Henriksson M, Heikkinen R, Puukko-Viertomies LR, Jahnukainen K. Sexual function in male long-term survivors of childhood acute lymphoblastic leukemia. Cancer. (2016) 122:2268-76. doi: 10.1002/cncr.29989

18. Joly F, Héron JF, Kalusinski L, Bottet P, Brune D, Allouache N, et al. Quality of life in long-term survivors of testicular cancer: a population-based casecontrol study. J Clin Oncol. (2002) 20:73-80. doi: 10.1200/JCO.2002.20.1.73

19. Mykletun A, Dahl AA, Haaland CF, Bremnes R, Dahl O, Klepp O, et al. Side effects and cancer-related stress determine quality of life in long-term survivors of testicular cancer. J Clin Oncol. (2005) 23:3061-8. doi: 10.1200/JCO.2005.08.048

20. Huddart RA, Norman A, Moynihan C, Horwich A, Parker C, Nicholls E, et al. Fertility, gonadal and sexual function in survivors of testicular cancer. $\mathrm{Br} \mathrm{J}$ Cancer. (2005) 93:200-7. doi: 10.1038/sj.bjc.6602677

21. Jonker-Pool G, Van de Wiel HB, Hoekstra HJ, Sleijfer DT, Van Driel MF, Van Basten JP, et al. Sexual functioning after treatment for testicular cancer-review and meta-analysis of 36 empirical studies between 1975-2000. Arch Sex Behav. (2001) 30:55-74. doi: 10.1023/A:1026468707362

22. Petrozzi A, Pallotti F, Pelloni M, Anzuini A, Radicioni AF, Lenzi A, et al. Inhibin B: are modified ranges needed for orchiectomised testicular cancer patients? Asian J Androl. (2018). doi: 10.4103/aja.aja_93_18 [Epub ahead of print].

23. Berger CC, Bokemeyer C, Schuppert F, Schmoll HJ. Endocrinological late effects after chemotherapy for testicular cancer. Br J Cancer. (1996) 73:110814. doi: 10.1038/bjc.1996.213

24. Bokemeyer C, Berger CC, Kuczyk MA, Schmoll HJ. Evaluation of longterm toxicity after chemotherapy for testicular cancer. J Clin Oncol. (1996) 14:2923-32. doi: 10.1200/JCO.1996.14.11.2923

25. Brennemann W, Stoffel-Wagner B, Helmers A, Mezger J, Jäger N, Klingmüller D. Gonadal function of patients treated with cisplatin based chemotherapy for germ cell cancer. J Urol. (1997) 158:844-50.

26. Nord C, Bjøro T, Ellingsen D, Mykletun A, Dahl O, Klepp O, et al. Gonadal hormones in long-term survivors 10 years after treatment for unilateral testicular cancer. Eur Urol. (2003) 44:322-8. doi: 10.1016/S0302-2838(03)00263-X

27. Lackner J, Schatzl G, Koller A, Mazal P, Waldhoer T, Marberger M, et al. Treatment of testicular cancer: influence on pituitary-gonadal axis and sexual function. Urology. (2005) 66:402-6. doi: 10.1016/j.urology.2005.03.050

28. Tasdemir C, Firdolas F, Harputluoglu H, Altintas R, Gunes A. Erectile dysfunction in testicular cancer patients treated with chemotherapy. Andrologia. (2012) 44:226-9. doi: 10.1111/j.1439-0272.2011.01271.x

29. Petersen PM, Giwercman A, Daugaard G, Rørth M, Petersen JH, Skakkeaek $\mathrm{NE}$, et al. Effect of graded testicular doses of radiotherapy in patients treated for carcinoma-in-situ in the testis. J Clin Oncol. (2002) 20:1537-43. doi: 10.1200/JCO.2002.20.6.1537

30. Lackner JE, Märk I, Schatzl G, Marberger M, Kratzik C. Hypogonadism and androgen deficiency symptoms in testicular cancer survivors. Urology. (2007) 69:754-8. doi: 10.1016/j.urology.2007.01.002

31. Eberhard J, Ståhl O, Cohn-Cedermark G, Cavallin-Ståhl E, Giwercman Y, Rylander L, et al. Sexual function in men treated for testicular cancer. J Sex Med. (2009) 6:1979-89. doi: 10.1111/j.1743-6109.2009.01298.x

32. Kim C, McGlynn KA, McCorkle R, Li Y, Erickson RL, Ma S, et al. Sexual functioning among testicular cancer survivors: a case-control study 
in the U.S. J Psychosom Res. (2012) 73:68-73. doi: 10.1016/j.jpsychores.201 2.02.011

33. Tal R, Stember DS, Logmanieh N, Narus J, Mulhall JP. Erectile dysfunction in men treated for testicular cancer. BJU Int. (2014) 113:907-10. doi: 10.1111/bju.12331

34. Kurobe M, Kawai K, Suetomi T, Iwamoto T, Waku N, Kawahara T, et al. High prevalence of hypogonadism determined by serum free testosterone level in Japanese testicular cancer survivors. Int J Urol. (2018) 25:457-62. doi: 10.1111/iju.13537

35. van Basten JP, Hoekstra HJ, van Driel MF, Koops HS, Droste JH, JonkerPool G, et al. Sexual dysfunction in nonseminoma testicular cancer patients is related to chemotherapy-induced angiopathy. J Clin Oncol. (1997) 15:2442-8. doi: 10.1200/JCO.1997.15.6.2442

36. van Basten JP, van Driel MF, Hoekstra HJ, Sleijfer DT. Erectile dysfunction with chemotherapy. Lancet. (2000) 356:169. doi: 10.1016/S0140-6736(05)73187-1

37. Mahmood J, Shamah AA, Creed TM, Pavlovic R, Matsui H, Kimura M, et al. Radiation-induced erectile dysfunction: recent advances and future directions. Adv Radiat Oncol. (2016) 1:161-169. doi: 10.1016/j.adro.2016.05.003

38. Jonker-Pool G, van Basten JP, Hoekstra HJ, van Driel MF, Sleijfer DT, Koops HS, et al. Sexual functioning after treatment for testicular cancer: comparison of treatment modalities. Cancer. (1997) 80:454-64. doi: 10.1002/(SICI)10970142(19970801)80:3<454::AID-CNCR13>3.0.CO;2-W

39. Aass N, Grünfeld B, Kaalhus O, Fosså SD. Pre- and post-treatment sexual life in testicular cancer patients: a descriptive investigation. $\mathrm{Br} J$ Cancer. (1993) 67:1113-7.

40. Hartmann JT, Albrecht C, Schmoll HJ, Kuczyk MA, Kollmannsberger C, Bokemeyer C. Long-term effects on sexual function and fertility after treatment of testicular cancer. Br J Cancer. (1999) 80:801-7. doi: 10.1038/sj.bjc.6690424
41. Tuinman MA, Hoekstra HJ, Vidrine DJ, Gritz ER, Sleijfer DT, Fleer J, et al. Sexual function, depressive symptoms and marital status in nonseminoma testicular cancer patients: a longitudinal study. Psychooncology. (2010) 19:23847. doi: 10.1002/pon. 1560

42. Wortel RC, Ghidey Alemayehu W, Incrocci L. Orchiectomy and radiotherapy for stage I-II testicular seminoma: a prospective evaluation of short-term effects on body image and sexual function. J Sex Med. (2015) 12:210-8. doi: $10.1111 /$ jsm.12739

43. Catanzariti F, Polito B, Polito M. Testicular prosthesis: patient satisfaction and sexual dysfunctions in testis cancer survivors. Arch Ital Urol Androl. (2016) 88:186-188. doi: 10.4081/aiua.2016.3.186

44. Böhlen D, Burkhard FC, Mills R, Sonntag RW, Studer UE. Fertility and sexual function following orchiectomy and 2 cycles of chemotherapy for stage I high risk nonseminomatous germ cell cancer. J Urol. (2001) 165:441-4. doi: 10.1097/00005392-200102000-00022

45. Deveci S, O'Brien K, Ahmed A, Parker M, Guhring P, Mulhall JP. Can the International Index of Erectile Function distinguish between organic and psychogenic erectile function? BJU Int. (2008) 102:354-6. doi: 10.1111/j.1464-410X.2008.07610.x

Conflict of Interest Statement: The authors declare that the research was conducted in the absence of any commercial or financial relationships that could be construed as a potential conflict of interest.

Copyright (C) 2019 Pallotti, Petrozzi, Cargnelutti, Radicioni, Lenzi, Paoli and Lombardo. This is an open-access article distributed under the terms of the Creative Commons Attribution License (CC BY). The use, distribution or reproduction in other forums is permitted, provided the original author(s) and the copyright owner(s) are credited and that the original publication in this journal is cited, in accordance with accepted academic practice. No use, distribution or reproduction is permitted which does not comply with these terms. 